ISSN: 2238-8052

\title{
PROCESSO PARTICIPATIVO DAS COMUNIDADES RURAIS NO “SEQUESTRO DO CARBONO" EM MOÇAMBIQUE
}

\author{
RURAL COMMUNITIES' PARTICIPATIVE PROCESS IN MOZAMBIQUE'S \\ "CARBON SEQUESTRATION"
}

André Camanguira NGUIRAZE 1

Artigo recebido em 13/05/2018 e aceito em 30/07/2018

Palavras-chave: Agroflorestamento; Comunidades Rurais; Créditos de Carbono; Participação e Regulado de Nhambita.
Keywords:

Agroforestry; Rural Communities;

Carbon Credits;

Participation

Nhambita

Community.

\section{R E S U M O}

Este artigo tem como objetivo principal apresentar algumas reflexões sobre a incorporação de práticas participativas e de mecanismos voltados para a articulação das comunidades rurais no processo de "sequestro de carbono", na zona tampão, do Regulado de Nhambita. Optou-se pela pesquisa-ação, nesta proposta, pois permitiu o acompanhamento e avaliação das ações realizadas em ações participativas das comunidades rurais moçambicanas no sequestro do carbono através do envolvimento no agroflorestamento. Assim, pela metodologia adotada, foi possível compreender os mecanismos da produção alimentar e os riscos de estarem seriamente comprometidas nesta atividade devido à implementação de projetos de plantio e conservação de árvores para a captura de carbono e à chamada Redução de Emissões por Desmatamento e Degradação Florestal Plus (REDD+). Tais projetos poderão conduzir as comunidades locais a graves situações de insegurança alimentar e resultar na perda da posse de terra e do controle de recursos florestais por parte de camponeses, tanto que o comércio de carbono e REDD+ readapta os camponeses a "cultivar" o carbono a serviço dos países poluidores.

\section{A B S T R A C T}

This article has as main objective present some reflections about the incorporation of participative practices and of rural communities directed mechanisms articulation in the process of "carbon sequestration", in the buffer zone, from Nhambita Community. The action research was chosen in this proposal, since it allowed the monitoring and actions evaluation carried out in participative actions of the Mozambican rural communities in the carbon sequestration through the involvement in agroforestry. Thus, through the methodology adopted, it was possible to understand the mechanisms of food production and the risks of being seriously compromised in this activity due to the implementation of projects of planting and conservation of trees for the capture of carbon and the socalled Reduction of Emissions from Deforestation and Forest Degradation Plus (REDD +). Such projects could lead local communities to severe food insecurity and result in the loss of land tenure and control of forest resources by peasants, so much so that carbon trading and REDD + readjust peasants to "cultivate" the carbon of polluting countries.

\footnotetext{
${ }_{1}^{1}$ Prof. Dr. da Universidade Zambeze, sediada na cidade da Beira, em Moçambique. E-mail: acamaguira@yahoo.com.br.
} 


\section{INTRODUÇÃO}

Este artigo tem como objetivo principal apresentar algumas reflexões sobre a incorporação de práticas participativas e de mecanismos voltados para a articulação de atores sociais, no processo de "sequestro de carbono", nas comunidades rurais de Nhambita e na Zona Tampão do Parque Nacional das Quirimbas.

Como sucede com outros parques em Moçambique, tanto dentro do Parque Nacional de Quirimbas, quanto no Parque Nacional de Gorongosa, existem assentamentos humanos com densidade populacional relativamente reduzida. A maior densidade populacional observa-se ao longo das principais estradas, enquanto que a menor densidade, nota-se nos postos administrativos no interior do Parque.

O Arquipélago das Quirimbas, em Cabo Delgado, é uma cadeia de 28 ilhas, que se estendem ao longo de quase 400 km, desde o norte da Cidade de Pemba, no sul, à Cidade de Palma, no norte. As 11 ilhas mais ao sul e uma extensa zona de floresta no continente estão incluídas no Parque, resultando numa área total de 750,639 ha, dos quais 598,402 ha são habitats terrestres e 152,237 ha são habitats marinhos e ilhéus. Esta área é de há muito reconhecida como uma zona de grande beleza paisagística, enorme biodiversidade de significado mundial e importante patrimônio histórico. A recomendação de que esta área seja declarada um parque nacional se remete ao ano de 1971. (WWF, 2005).

Tornou-se mais aceito, nos últimos anos, em Moçambique, a ideia da participação na mitigação dos efeitos do aquecimento global, através da criação de mecanismos que possibilitem a participação das comunidades rurais no "sequestro de carbono", nas zonas tampões, dos Parques Nacionais, como é o caso do Parque Nacional de Gorongosa e das Quirimbas.

A crescente difusão desse enfoque pode ser atribuída, por um lado, pela tendência dos países centrais a continuar a poluir e, por outro, pela nova abordagem que se tornou dominante, no contexto da participação das comunidades rurais no agroflorestamento, ou seja, a prática da agricultura de conservação, que enfatiza o desenvolvimento local e a articulação dos atores sociais.

\section{COMUNIDADES DA ZONA TAMPÃO DO PARQUE NACIONAL DAS QUIRIMBAS}

O Parque Nacional das Quirimbas, ocupa uma área de $7.500 \mathrm{~km}^{2}$, abrangendo ecossistemas marinho e terrestre. Foi estabelecido através do Decreto 14/2002, de 6 de Junho.

O Parque abrange a parte Norte do Distrito de Pemba-Metuge. Há duas aldeias que estão na zona de proteção total, quais sejam Soco e Namau. Nesta zona, não são permitidas quaisquer atividades de extração de recursos e os ecossistemas são protegidos até a um nível possível dos efeitos 
danosos da atividade humana, permitindo atividades de investigação científica e turismo controlado (RESE, 2016).

À semelhança de quase todos os distritos abrangidos pelo Parque Nacional das Quirimbas, em Ancuabe, a maior parte dos ocupantes e usuários de Terra não têm o Direito de Uso e Aproveitamento da Terra (DUAT) ou qualquer outro documento legal. 0 Direito de Uso e Aproveitamento da Terra (DUAT) é reconhecido nos termos costumeiros, sendo a maior parte da terra comunitária, cujos direitos de uso são passados de uma geração, através de herança dentro dos arranjos familiares (MAE, 2005).

Mapa 1: Situação Geográfica do PNQ

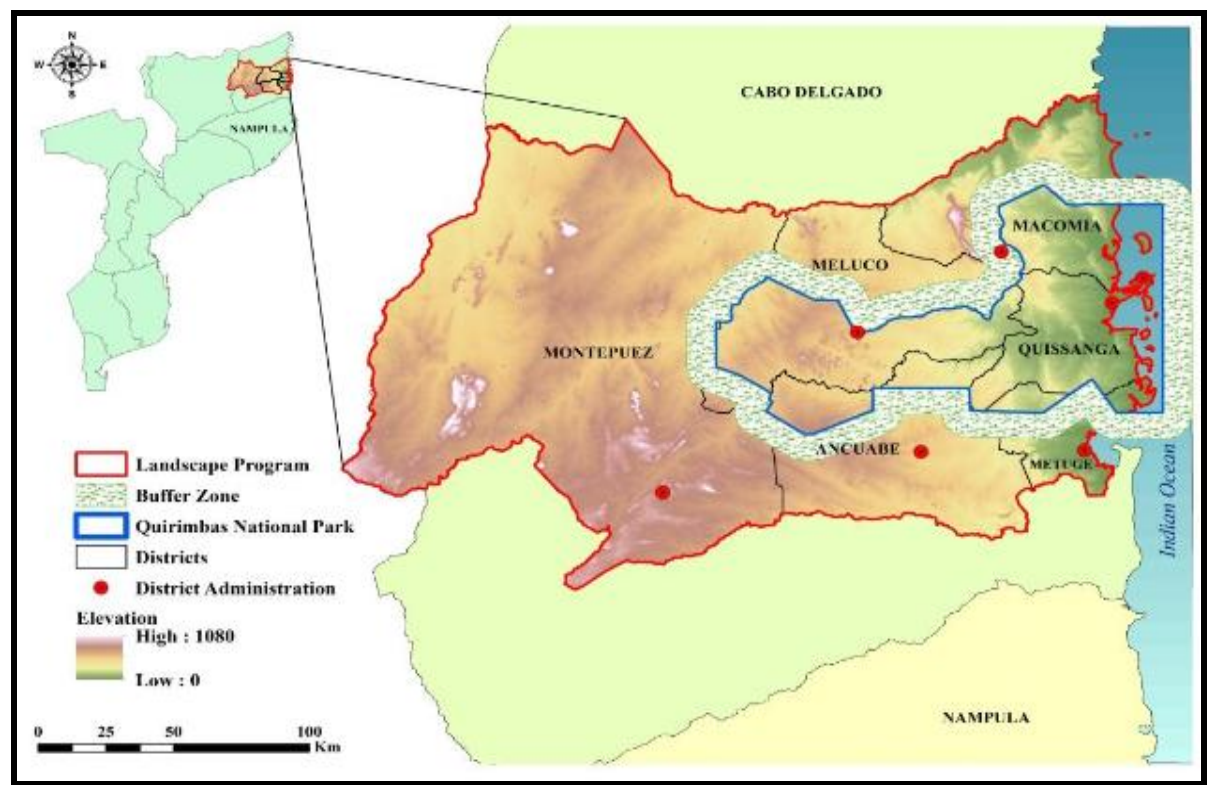

Fonte: Relatório Final - FUNAB (UT-REED+), 2016.

A Zona Tampão do Parque, abrange 13 aldeias, chamadas de Unidades: 25 de Junho, Nanjua, Nacuta, Tratara, Mueve, Milamba, Messanja, Ntessa, Miquindane, Gimpiria, Londo e Namiteue. Esta zona é formada por uma faixa de $10 \mathrm{Km}$ de largura, à volta dos limites do Parque e, segundo o plano de manejo, deveria ser limitada às atividades ligadas à conservação, à criação de animais, ao desenvolvimento do turismo e outras do gênero (DPCAA - Cabo Delgado, 2007).

\section{COMUNIDADE DE NHAMBITA - PARQUE NACIONAL DE GORONGOSA}

A área em questão está situada nos limites sudeste do Parque Nacional de Gorongosa ${ }^{2}$. 0 Parque encontra-se, aproximadamente, a 60 km da sede Municipal de Gorongosa.

\footnotetext{
2 Parque Nacional Gorongosa: os $4.000 \mathrm{~km}^{2}$ do Parque estão localizados nos extremos sul do grande Vale do Rift Africanos, na província Moçambicana de Sofala. O Parque inclui o vale e uma parte dos planaltos que o circundam. Os rios que nascem na vizinha serra de Gorongosa irrigam suas planícies.
} 
Ao Sul do referido Parque, corre o Rio Púngué e, a oeste do mesmo, o Rio Vanduzi. A área total do Régulo de Chicare é da ordem de $20 \mathrm{~km}^{2}$, com cerca de 1.100 famílias espalhadas nos cincos bairros, ali existentes: Nhambita, Bué Maria, Munhanganhe, Púngué e Mbulawa (Mapa 2).

As terras da comunidade de Nhambita foram legalizadas em 2003, depois de serem enquadradas no novo registo de terras 19/97, permitindo, assim, o direito de propriedade das terras ancestrais, nelas legitimando a gestão dos recursos naturais. A comunidade de Nhambita é considerada como comunidade na Lei das Terras, sendo entidade privada e titular de um direito exclusivo (NGUIRAZE, 2013).

Mapa 2: Situação Geográfica da Comunidade de Nhambita

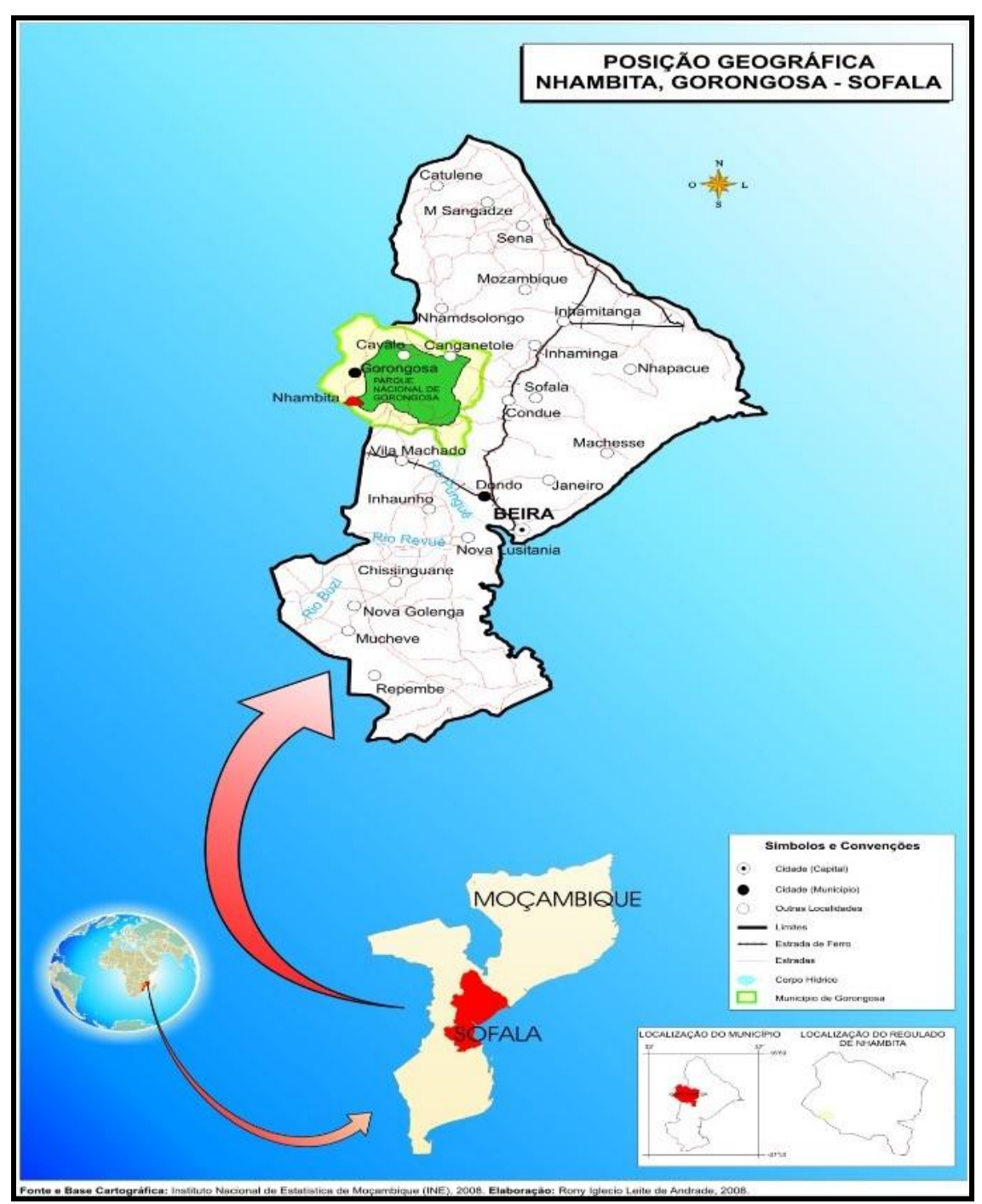

Fonte: Instituto Nacional de Estatística de Moçambique (INE), 2008.

Elaboração: Rony Iglecio Leite de Andrade, 2008. 
Por lei, todos os "não lideres" numa comunidade são co-titulares do direito comunitário, de uso e aproveitamento da terra (TANNER; BALEIRA et al, 2004).

Por outro lado, a comunidade, no Decreto 15/2000, é definida de outra forma, incluindo todos os que vivem dentro de uma certa unidade de organização territorial, chamada localidade, posto administrativo e distrito.

\section{A PRÁTICA DO AGROFLORESTAMENTO NAS ZONAS TAMPÕES NOS DOIS ECOSSISTEMAS}

Partindo do pressuposto de que as causas da degradação das florestas são várias e complexas, todas elas têm um denominador comum que é o próprio Homem. As comunidades mais pobres degradam as florestas para o seu próprio sustento. Muitos outros, participam da sua degradação para fins lucrativos e, na maioria dos casos, com a anuência e incentivo do Estado.

O desmatamento, a conversão das florestas, as queimadas, entre outras formas de degradação ambiental, não só contribuem para o agravamento das mudanças climáticas, através da redução da capacidade de absorção e armazenamento dos $\mathrm{GEE}^{3}$, como também, comprometem a sobrevivência de cerca de $70 \%$ da população. As florestas em Moçambique suportam mais de $60 \%$ da população que vive nas zonas rurais e, cerca de $85 \%$ das necessidades energéticas advêm, da energia da biomassa (lenha e carvão) (ZOLHO, 2010).

Não obstante, nos últimos tempos, as iniciativas internacionais têm conhecido um crescimento em termos de intervenção na mitigação dos efeitos das mudanças climáticas. 0 sequestro de carbono é uma iniciativa internacional que surgiu da implementação do Protocolo de Kioto, pelos países desenvolvidos. A iniciativa se baseia no pressuposto de que as árvores, durante o seu crescimento e, através do processo da fotossíntese, absorvem (sequestram), o Dióxido de Carbono, da atmosfera. Assim, plantando-se mais árvores, reduzir-se-ia a concentração desse gás, que é o principal, no aquecimento global. Portanto, as grandes companhias ou individualidades poluidoras poderiam pagar avultadas somas para o estabelecimento de matas florestais como forma de compensação pelos atos das suas indústrias.

Todavia, esta iniciativa não está tendo grande sucesso e, envolvidas em grandes controvérsias, pelo fato dos poluidores poderem continuar a poluir, bastando apoiar o plantio de árvores. Outra discórdia que a iniciativa encontrou foi o preço do carbono, particularmente, na África, onde ainda não existe uma quantificação do volume de carbono de cada espécie de árvores. Por essa razão, as empresas intermediárias (entre poluidor/comprador e produtor/vendedor) estabelecem o preço e a modalidade de pagamento a seu bel prazer.

\footnotetext{
3 Gases de Efeito Estufa (GEE): São substâncias gasosas que absorvem parte da radiação infravermelha, emitida principalmente pela superfície terrestre, dificultando seu escape para o espaço. Isso impede que ocorra uma perda demasiada de calor para o espaço, mantendo a Terra aquecida.
} 
No entanto, em Moçambique, a primeira iniciativa de "sequestro de carbono" teve início em 2003, pela empresa Evirotrade Ltda ${ }^{4}$, na comunidade de Nhambita, Zona Tampão do Parque Nacional da Gorongosa. Devido à problemática dos preços de carbono, a empresa integrou outros componentes como atividades agroflorestais, como a carpintaria, utilizando troncos abandonados ou queimados, apicultura, entre outros (ZOLHO, 2010).

A iniciativa se baseou no princípio de que os países dispostos e, em condições de reduzir emissões por desmatamento, deveriam ser compensados financeiramente. Por esse motivo, os mecanismos do REDD 5 pretendem alcançar, simultaneamente, a redução das emissões, participar na redução da pobreza, conservar a biodiversidade e atuar na manutenção dos serviços ecossistêmicos.

Alguns dos desafios que o REDD enfrenta é a competição com outras formas de uso da terra, consideradas essenciais para o desenvolvimento socioeconômico do País, particularmente, a produção alimentar, biocombustíveis e a expansão de infraestruturas sociais. Outro desafio, não menos importante, é a capacidade metodológica de quantificação do volume de carbono que as florestas detêm e, que pode ser mantido, servindo como a base de qualquer negociação da compensação, no âmbito da implementação do REDD.

Apesar destes e outros constrangimentos, considera-se que o atual quadro jurídico-legal, arranjo institucional e as experiências que o país tem na implementação dos projetos comunitários de gestão dos recursos naturais são condições positivas para a implementação desta iniciativa (NHANTUMBO E IZIDINE, 2009).

\section{MECANISMO DE PARTICIPAÇÃO DAS COMUNIDADES NO “CULTIVO” DE CARBONO}

0 projeto pretende restaurar e proteger, num período de 50 anos, uma área aproximadamente de 7.000 ha de florestas tropicais, parcialmente degradadas. 0 projeto abrange, também, a agricultura familiar de agroflorestamento, na esfera da agroecologia, com o objetivo de aliviar a pressão antrópica, provocada por uma combinação de fatores, entre os quais se destacam: o corte ilegal e desregrado de certas espécies de madeiras, a exploração de carvão vegetal, a agricultura itinerante, as queimadas florestais, a caça furtiva, entre outros problemas identificados. 0 projeto tem, ainda, o propósito de proteger o plantio de árvores nativas como é o caso do miombo e chanfuta, concebendo, além disso, a garantia efetiva da utilização regrada do patrimônio florestal, em benefício de todos, especialmente das comunidades locais.

\footnotetext{
${ }^{4}$ Envirotrade: agência patrocinada pelos países da União Europeia, envolvida com o plantio de árvores nativas, através de projetos de geração de renda na comunidade de Nhambita, para a absorção do dióxido de carbono, em excesso na atmosfera, principal gás responsável pelo aquecimento global.

${ }^{5}$ REDD (Redução de Emissões por Desmatamento e Degradação): iniciativa que emergiu a partir da 11 a Conferência das Partes do Quadro das Nações Unidas para as Mudanças Climáticas (2005).
} 
O regulado de Chicare apresenta um Comitê de Gestão dos Recursos Naturais, bem como detém uma Associação, fundada em 2001. As suas terras, pelo fato de terem sido delimitadas e legalizadas, em 2003, nos termos da Lei de Terras, ajudam a promover o desenvolvimento pessoal e comunitário. Segundo os entrevistados, a legalização das terras, naquela comunidade, visou garantir a segurança da posse da terra que é essencial para o projeto de sequestro de carbono, minimizando a incidência de conflitos locais.

Todavia, com base nas entrevistas efetuadas junto aos membros da comunidade, constatou-se que pouco tem sido feito em relação aos benefícios comuns, porque a preocupação central das agências gestoras do Parque Nacional é o reflorestamento e o sequestro do carbono, o que significa uma disparidade de benefícios entre os investidores e a comunidade local.

Os camponeses de Nhambita participam deste projeto com a perspectiva de que os certificados de redução de emissão de carbono poderiam ser, eventualmente, negociados nos mercados globais, como créditos comercializáveis (SMITH E SCHERR, 2003). As nações desenvolvidas deveriam pagar pelo reflorestamento aos países em desenvolvimento, por serviços prestados por suas árvores, em sequestro de carbono atmosférico, na proporção de 50 pés de árvores/120,00 USD anuais (2007), no período de sete anos vegetativos.

Os gestores das agências de sequestro partem da metodologia de co-responsabilidade de diferentes atores envolvidos no processo, atuando como protagonistas na construção social, na perspectiva de uma nova concepção de mundo, de trabalho e de mercado. Para isso, as agências executoras (Envirotrade e PNG), incentivaram a ampliação do número de entidades associativas na comunidade, anunciando a necessidade de ações conjuntas e em rede, como forma de envolvimento da comunidade no processo de reflorestamento, o que propiciou a sobrevivência e a conquista de novos espaços para o Regulado que é assolado, com frequência, pelo flagelo da seca e da fome, acentuando a sua fragilidade econômica.

De acordo com os entrevistados, os comitês e as associações foram concebidas, a partir de condições impostas pelas agências, que atuam na região, as quais exigem um vínculo com entidades representativas, de caráter associativo, visando coletivizar as ações na gestão dos recursos.

Para viabilizar as ações previstas foram considerados quatro fatos adicionados aos projetos, como decisivos no desenrolar do processo e fundamentais para sua sustentabilidade: a organização de base da comunidade e a realização de contratos; a legalização do Direito de Uso e Aproveitamento da Terra; o mapeamento geográfico das machambas (roças), para evitar os possíveis conflitos de terras e a distribuição das mudas e dos insumos agrícolas, dentro da elaboração do planejamento participativo, além da definição do plano de capacitação dos agricultores, envolvidos no trabalho coletivo, tendo como filosofia, as práticas associativas. 
As compensações de carbono são criações totalmente artificiais, sendo um produto comercial, baseado num bem invisível e incorpóreo - carbono armazenado - e, tal como o caso de mercadorias mais corpóreas, o preço flutua de acordo com a procura e a oferta. Alguns críticos afirmam que o crédito de carbono é apenas um modo de aliviar a consciência dos países industrializados e que os benefícios não chegam até as comunidades pobres. De acordo com a Komadir et al (2012) são lançadas advertências para o perigo de transformar as terras produtoras de alimento da África, com o intuito de obter carbono, a fim de que os países ricos possam evitar cortar as emissões de GEE. Tal como afirma Helena Paul, da ONG ambiental EcoNexus, citado por Komadir et al (2012, p. 14) "existe, aqui, um enorme perigo para a agricultura e apropriação de terras para a expansão de culturas com o propósito de angariar créditos".

Observou-se na pesquisa, que os projetos de sequestro de carbono produziram diminutas receitas para os agricultores de Nhambita, permitindo que os poluidores continuem a poluir do outro lado do planeta. Portanto, a inexistência de um método fidedigno para calcular quanto os agricultores estão retirando carbono da atmosfera, através de práticas melhoradas, constitui um sério obstáculo para o projeto de desenvolvimento local.

\section{AS RELAÇÕES INTERINDIVIDUAIS NO PROCESSO DE SEQUESTRO DO CARBONO}

Na comunidade, os agricultores assinaram, voluntariamente, contratos com a agência de implementação Envirotrade (uma companhia com sede no Reino Unido), para o plantio de plantas indígenas (miombo, pangapanga e chanfuta, etc) e, frutíferas nas suas fazendas (tanto nos limites das propriedades, como em linhas intercaladas com as outras culturas) e para as gerirem, durante 25 anos, em troca de pagamentos anuais em dinheiro.

O objetivo do projeto de Nhambita é fixar o carbono, através do plantio e, posteriormente, vender os créditos de carbono no mercado internacional de carbono. 0 projeto abrange, também, outras atividades como a carpintaria, a apicultura, a construção de viveiros, dando emprego em tempo integral a aproximadamente 140 pessoas e, oferecendo, inclusive, emprego sazonal limitado, na área da prevenção de incêndios florestais e de atividades de patrulha.

A própria ideia de participação induzida por essas agências tem um efeito perverso na comunidade, no caso concreto das atividades de recuperação dos ecossistemas, na Zona Tampão do Parque Nacional de Gorongosa (PNG). 0 reflorestamento desenvolvido na comunidade de Nhambita (Nhambita Comunity Carbon Projet), através da metodologia participativa, vinculada à agência Envirotrade, tem como objetivos essenciais, a implementação de projetos de plantio e conservação de árvores para a captura de carbono, além da chamada Redução de Emissões por Desmatamento e 
Degradação Florestal Plus (REDD+), bem como a comercialização dos chamados créditos de carbono, no mercado voluntário (Europa e EUA).

As atividades de reflorestamento de tais projetos poderão conduzir o País a graves situações de insegurança alimentar e resultar na perda da posse da terra e dos contratos de recursos florestais por parte das comunidades locais.

A comunidade de Nhambita desconhece os conceitos de REDD e sequestro de carbono e, apesar de alguns camponeses saberem que plantam árvores e conservam as florestas para vender o carbono, demostram desconhecer as ideias e os mecanismos que norteiam a sua própria ação, na atividade florestal supracitada (UNAC, 2012).

É comum as agências financiadoras externas exigirem a participação funcional, como contraparte dos beneficiários, para reduzir custos. Este tipo de participação pode, eventualmente, abrir espaço para pequenas decisões, desde que, as principais, já estejam definidas (YU, 2004, p. 117).

Ao se analisar a ocupação e o trabalho da mulher nesse projeto, os dados da pesquisa mostram que 58\% das entrevistadas participam, ativamente, do sequestro do carbono, incentivadas pelos fatores culturais que fundamentam as responsabilidades atribuídas e alicerçadas na organização do trabalho, ainda que, as atividades realizadas por elas na machamba do milho, não sejam consideradas trabalho e, sim, tarefa doméstica. Entretanto, as atividades realizadas pelas mulheres, no âmbito do agroflorestamento, são consideradas, apenas, como ajuda ao homem, os quais têm contrato de provisão de carbono com a Envirotrade. No entanto, no espaço rural, essa condição como atesta Osório (2006, p.10), "na divisão do trabalho, a mulher é representada como força de trabalho, mas não sujeito das divisões sobre o produto do esforço despendido".

Os resultados da pesquisa evidenciam que há insegurança quanto à atividade e à tendência ao abandono do plantio de árvores, pelo fato de tais serviços serem considerados de parcos rendimentos para a comunidade local.

O enfoque nos valores econômicos na conservação das florestas comunitárias, promovido pela Envirotrade, poderão não tornar os valores culturais, espirituais e biológicos mais importantes, como sempre foram para as comunidades que sempre souberam conservar as florestas por gerações e gerações (SPIRIC, 2009, p. 26).

Apesar das dificuldades já discutidas, os dados revelam a adesão da comunidade do Regulado ao agroflorestamento como atividade produtiva e socializante, uma vez que, o indivíduo sente a necessidade de unir-se ao seu próximo, consciente que deve cooperar e aglutinar o interesse pessoal aos da comunidade. 


\section{A CONFIGURAÇÃO ESPACIAL DO PROCESSO PARTICIPATIVO}

Na comunidade de Nhambita percebeu-se que o nível de participação de membros da comunidade nos projetos foi limitado. Assim, a existência do mercado do carbono deveria sinalizar a relevância econômica da proteção de áreas florestais e de outros serviços ambientais, tais como: a gestão das bacias hidrográficas (pelo controle de enchentes ou purificação das águas e de regulação do clima), a biodiversidade e o ecoturismo no território.

0 projeto de sequestro do carbono, sediado na comunidade, conforme a pesquisa feita, mostrou a fragilidade da condição econômica dos membros da comunidade. Além disso, a implementação do aludido projeto, tende a atrofiar as formas coletivas de organização do trabalho, comprometendo as possibilidades de uma sociabilidade mais viva e de uma cultura mais harmônica.

Depreende-se que as machambas dos membros das comunidades, já estão envolvidas com os interesses e propósitos da Envirotrade e do Parque Nacional de Gorongosa, expressando os interesses ligados ao comércio de créditos de carbono e, não mais, comprometidos com a unidade das relações sociais e ecológicas que, precedentemente, caracterizavam o equilíbrio social da comunidade.

\section{CONSIDERAÇÕES FINAIS}

Pelo exposto, foi nesse contexto que, com o objetivo de aglutinar as iniciativas locais e o impulsionamento de arranjos institucionais, a partir de 2000, que a comunidade foi instada a participar na gestão dos recursos naturais da Zona-Tampão do Parque, para promover novos debates e lidar com questões que exigiam respostas criativas e inovadoras, como foi o caso da implementação do processo de gestão da produção de colmeias convencionais. Outrora, a comunidade praticava a atividade orientada para a produção de mel, utilizando métodos tradicionais (colmeias de cortiça, feita de casca de árvores) e queimadas descontroladas. A iniciativa consistiu em transformar parte dos membros das comunidades, em criadores de abelhas.

Houve, portanto, uma mudança de paradigma na formação de novos sistemas de dependência ecológica, no qual a valorização das autoridades tradicionais comunitárias e a vida do grupo de vizinhança passou a perder a sua autonomia, dependendo das novas esferas de relações, através do surgimento de novos cenários socioespaciais. A Zona-Tampão do Parque Nacional de Gorongosa parece ter atraído investimentos privados, devido aos seus componentes, facilitando o advento de novos empregos e atividades turísticas.

Nota-se que, a exploração do ecoturismo e do sequestro do carbono, pela agência Envirotrade, a nova dinâmica do Parque Nacional de Gorongosa (PNG) e o Centro de Desenvolvimento Comunitário 
(CDC) têm condições de atrair para o regulado de Chicare, a internet e a telefonia móvel que poderão contribuir para as mudanças do comportamento e dos padrões de consumo da população local.

Apesar das mudanças sociais até aqui discutidas, a comunidade de Nhambita prossegue realçando a importância das práticas tradicionais como fatores de sobrevivência do grupo, mostrando a importância da permanência de tais costumes, apesar das transformações ocorridas no ritmo da vida cotidiana da sua comunidade. As representações das práticas culturais familiares aparecem ambientadas como resquícios ou traços de experiências vivenciadas em outros tempos e contextos.

\section{REFERÊNCIAS}

DPCAA - Direcção Provincial para a Coordenação da Acção Ambiental de Cabo Delgado. Plano de Uso da Terra - Documento de Análise. p. 182. Pemba, 2007.

FUNAB - FUNDO DO AMBIENTE. Relatório Final (UT-REED+). Estudo das Causas de Desmatamento e da Degradação Florestal no Distritos Abrangidos pelo Programa de Gestão Integrada de Paisagens de Cabo Delgado (PROGIP_CD). Andrade F. Egas (Coordenador). Maputo, 2016.

KOMADIR et al. Mercado de Carbono: a quem beneficiam? In: Revista EPORO - Revista de Informação sobre o Desenvolvimento Agrícola e Rural nos Países ACP, n.109, jun/jul, 2012.

MAE - MINISTÉRIO DE ADMINISTRAÇÃO ESTATAL - Perfil do Distrito de Ancuabe. Província de Cabo Delgado. Criação do Parque Nacional de Quirimba - PNQ (2002) - Território do Distrito de Meluco. p. 51. MAE: Maputo, 2005.

NGUIRAZE, A. C. Identidade e Participação da Comunidade Rural nos Processos de Desenvolvimento Local: desafios e competências do Regulado de Nhambita-Mocambique. Tese de Doutorado em Ciências Sociais. Universidade Federal do Rio Grande do Norte (UFRN), Natal, 2013. Disponível em:

https://repositorio.ufrn.br/jspui/bitstream/123 456789/13822/1/AndreCN_TESE.pdf. Acesso em: s/d, 2017.

NHANTUMBO, I. \& IZIDINE, S. Preparing for REDD in Dryland Forests: investigating the options and potential synergy for REDD payments in the Miombo Eco-Region. Mozambique Country Study: IIED, 2009.

OSÓRIO, C. Women and Low in Southem. In: África Outra Vozes. WLSA. n.15. Maputo, 2006.

RESE - Relatório de Estudo Socioeconômico. Caracterização dos Distritos abrangidos pelo
Parque Nacional das Quirimbas. RESE: DPA, 2016.

SMITH \& SCHERR. Carbono Storege and Livellihoods Generetion Through Improved. San Francisco: Association of American Geographers, 2003.

SPIRIC, J. Investigating the Socio-economic Impact of REDD Scheme Implemented in the Nhambita Community Carbon Project. Tese de Mestrado. MSc-Joint European Master in Environmental Studies (JEMES). Barcelona: Universitat Autònoma de (UAB), 2009. Mozambique, 2009.

TANNER, C.; BALEIRA, S. A Legislação sobre o Acesso aos Recursos Naturais em Moçambique: o impacto das novas leis e das consultas comunitárias sobre o bem-estar a nível local. Com base no trabalho de campo de Ângelo Afonso, João Paolo Azevedo, João Bila, Constantino Chichava, Altino Moisés, Carlos Pedro e José Santos. Matola, 2004. Disponível em: www.saber.ac.mz/.../DEI_04_Legislacao_acesso_ recursosnaturais.pdf. Acesso em: s/d.

UNAC - UNIÃO NACIONAL DE CAMPONESES. Comércio de Carbono e REDD+ em Moçambique: camponeses "cultivam" carbono ao serviço de poluidores. Maputo, 2012. Disponível em: www.unac.org.mz/.../29-comercio-de-carbonoe-redd-em-mocambique-camponeses-cultivamcarbono-ao-servico-de-poluidores. Acesso em: s/d.

WWF. Parque Nacional de Quirimbas. Disponível em: https://www.wwf.org.mz/ o_que_fazemos/áreas_geograficas/qnp/ Acesso em: s/d, 2005.

YU, C. M. Sequestro Florestal de carbono no Brasil: Dimensões políticas, socioeconômicas e ecológicas. São Paulo: Annablume IEB, 2004.

ZOLHO, R. Mudanças Climáticas e as Florestas em Moçambique. Maputo: CIP, 2010. 